\title{
APUNTES SOBRE UNA FAMILIA DE LA OLIGAR- QUÍA LEONESA ENTRE LOS SIGLOS XV Y XVII: LOS FERNÁNDEZ DE LEÓN-VACA
}

\author{
Elena OSORIO ALONSO \\ Universidad de León
}

\begin{abstract}
RESUMEN: En este artículo se hace un recorrido por la historia de la familia leonesa Fernández de León-Vaca a lo largo de los siglos XV a XVII tomando como base un diploma pontificio dirigido a los fundadores de la familia y unas extensas notas marginales que ocupan los márgenes de este pergamino.

PALABRAS CLAVE: Oligarquía leonesa. Fernández de León-Vaca. Iglesia de Nuestra Señora del Mercado. Diplomática pontificia.

ABSTRACT: This article analyses the story of Fernández de León-Vaca family through two centuries (15th-17th), using a pontifical document and marginal notes, which are writen in the same parchment.
\end{abstract}

KEYWORDS: Oligarchy from León. Fernández de León-Vaca. Saint Mary of the Market Church. Pontifical Diplomatic.

El origen de este trabajo se sitúa en el hallazgo de un documento poco común en el archivo del monasterio de San Isidoro de León. Se trata de un diploma del Papa Eugenio IV concediendo la gracia de un altar portátil a Diego Fernández de León y a su esposa, María Vaca, miembros de la oligarquía leonesa del siglo XV.

Resulta poco habitual, en primer lugar, por el hecho de que no existe una relación aparente con el monasterio en cuyo archivo se ha encontrado. San Isidoro de León custodia cerca de cien pergaminos originales de la época medieval y moderna intitulados por el Papa y todos ellos van dirigidos o hacen referencia a abades, priores u otros cargos relacionados de algún modo con dicho monasterio. 
La única excepción que se ha encontrado es el diploma protagonista de este trabajo ${ }^{1}$.

En segundo lugar, hay que señalar la existencia de unas extensas notas marginales, añadidas a principios del siglo XVII, que ocupan el margen izquierdo y toda la parte inferior del pergamino y apuntan datos sobre los personajes a quienes está dirigido el documento y sobre sus descendientes. Este tipo de anotaciones tampoco se ha visto en ningún otro documento original papal de este archivo leonés.

Comprobada la singularidad de este documento, se intentará situar a la familia Fernández de León-Vaca ${ }^{2}$, destinataria del mismo, en el contexto del León del siglo XV. A comienzos de siglo, era una ciudad de unos cinco mil habitantes ${ }^{3}$ con tres zonas principales de población ${ }^{4}$ : la ciudad vieja, el Burgo Nuevo y los suburbios, entre los que destacan Santa Ana y Renueva, aunque conforme avanzan los años la zona artesanal y comercial del Burgo Nuevo se va a ir extendiendo también a la parte vieja, hasta entonces eminentemente eclesiástica y señorial, haciendo que estas divisiones tradicionales ya no concuerden muy bien con la realidad de la ciudad y se pueda señalar como nuevo eje de la misma la calle de la Ferrería de la Cruz, al norte de la cual quedaba la Catedral, el Palacio Episcopal, San Isidoro y algunas casas de la nobleza, mientras al sur quedaban algunas casas señoriales, pero también la calle de la Rúa y Frenerías, donde se encontraba la iglesia de Nuestra Señora del Camino, también llamada de los Francos y posteriormente conocida como del Mercado. Esta iglesia merece una mención especial respecto a otras de la ciudad de León porque existe una estrecha relación entre ella y la familia protagonista de este trabajo, como más adelante se concretará.

${ }^{1}$ Se han estudiado los pergaminos conservados en el Archivo del Monasterio de San Isidoro e intitulados por un Pontífice desde el siglo XV al XIX. Todos ellos aparecen citados, aunque de manera muy general y a veces incorrecta, enPÉREz LlAMAZARES, J. (1923). Catálogo de los códices y documentos de la Real Colegiata de San Isidoro de León. León.

${ }^{2}$ Se utiliza este apellido compuesto para referirse al matrimonio formado por Diego y María y a sus descendientes directos, aunque ya su hijo simplifica el apellido haciendose llamar indistintamente Vaca o Cabeza de Vaca, sin referencias a Fernández de León.

${ }^{3}$ Santamarta Luengos, J.M. (1993). Señorío y Relaciones de poder en León en la Baja Edad Media (Concejo y Cabildo Catedral en el siglo XV). León, p.27. Este autor señala la existencia de un estancamiento, pues Carlos ESTEPA DíEZ manejaba esas mismas cifras ya para el siglo XIII.

${ }^{4}$ Merino Rubio, W. (1972). «León en el siglo XV». Tierras de León 15, pp. 17-62. 
La vida política municipal ${ }^{5}$ se componía de un cuerpo central constituido en el siglo XV por ocho regidores que formaban el regimiento de la ciudad y luego una corporación más amplia en la que constan el juez del rey, los alcaldes de la villa y un escribano. A lo largo de este siglo la corporación municipal leonesa sigue una trayectoria similar a la del resto de municipios sometidos a la doble presión del rey, que trata de dominarlos mediante el nombramiento regular de corregidores desde los Reyes Católicos ${ }^{6}$, y de la nobleza, que ocupa la práctica totalidad de los cargos municipales por medio de las oligarquías urbanas. Dentro de éstas es donde se sitúan los Fernández de León-Vaca, familia protagonista de este trabajo.

La oligarquía leonesa ${ }^{7}$ está formada por una serie de familias que llega a copar los puestos políticos de la ciudad, pero siempre bajo el amparo de algún gran noble ${ }^{8}$. Este grupo social se compone de elementos bastante heterogéneos; artesanos, mercaderes, cargos de la Corte que desempeñan también funciones en la administración municipal, caballeros locales y pequeña nobleza, pero los enlaces matrimoniales acaban consolidando un patriciado urbano que junto con la gran nobleza controla los principales bienes y medios de la ciudad de León. Además de los Fernández de León-Vaca se pueden señalar también como miembros de este grupo a los Neira, Garavito, Robles, Villamizar o Villafañe.

Así pues, en esta situación de luchas de poder y de transformación de las estructuras urbanas vivieron los destinatarios del documento pontificio que ha dado lugar a este artículo, Diego Fernández de León y su esposa. El diploma papal nombra a "Didaco Fernandi de Leon, domino loci de Pobladura", aunque, al referirse a su mujer, en lugar de su nombre aparece un espacio con dos puntos. Este hecho es muy común en los documentos pontificios, pues ante la posibilidad de

${ }^{5}$ Para una visión más general de la vida política en las ciudades castellanas: LADERO QUESADA, M.A.(1994). «Monarquía y ciudades de realengo en Castilla siglos XII a XV» Anuario de Estudios Medievales 24, pp. 719-773.

${ }^{6}$ Existen nombramientos de corregidores ya en el siglo XIV, pero de un modo inconstante, hasta que los Reyes Católicos den estabilidad al cargo, haciendo nombramientos regulares.

7 Álvarez Álvarez, C. (1999). «Linajes nobiliarios y oligarquías urbanas en León» La Nobleza Peninsular en la Edad Media. VI Congreso de Estudios Medievales. León, pp.35-65. Tema tratado también por SANTAMARTA, Señorío..., pp.83-95.

${ }^{8}$ Para un conocimiento mas profundo del tema Monsalvo ANTÓN, J.M. (1993). «Parentesco y sistema concejil. Observaciones sobre la funcionalidad política de los linajes urbanos en Castilla y León (siglos XIII-XV)» Hispania 53:185, pp. 937-969. Aunque según este autor, siguiendo al profesor SANTAMARTA, en León las noticias sobre bandos urbanos en relación con el gobierno de la ciudad son vagas y parecen negar una institucionalización, que sí fue efectiva en otras ciudades castellanas. 
equivocarse en el nombre o de que el destinatario enviudase y se casara de nuevo, al omitirlo se está concediendo la gracia de una manera más amplia. Aun así, aunque no se la nombre, se sabe que la mujer de Diego Fernández era María Vaca y antes de conocerse este documento, fechado en 1435, la primera noticia sobre ella databa de $1439^{9}$.

También es destacable y novedosa la intitulación de Diego como "señor de Pobladura". Parece lógico pensar que se trate de Pobladura de los Oteros, ya que tenía posesiones en esa zona, pero por los datos conocidos hasta este momento se pensaba que el título de señor lo había obtenido su hijo Alonso Vaca ${ }^{10}$.

El resto del documento, en el que se concede la gracia de un altar portátil ${ }^{11}$ a la familia Fernández de León-Vaca, no ofrece otras novedades a nivel histórico, desarrollándose conforme a la formulística propia de este tipo de concesiones pontificias $^{12}$, que será explicada en un estudio diplomático al final de este trabajo.

Sin embargo, las singulares notas marginales que rodean el documento sí son una fuente importante de datos sobre el devenir histórico de la familia Fernández de León-Vaca desde el siglo XV al XVII. Están escritas en letra humanística y su autor, un miembro de la familia Vaca, se va dando a conocer a medida que las escribe. Al tratarse de hechos ocurridos en un largo lapso de tiempo, algunos bastante lejanos al autor de las notas, se va a ir intentando verificar el contenido de las anotaciones con los datos conocidos documentalmente sobre esta familia.

9 Álvarez Álvarez, C. (1995). Colección documental del archivo de la Catedral de León, XII (1351-1474), Colección Fuentes y Estudios de Historia leonesa, 60, León. El documento al que se hace referencia es el número 3523.

${ }^{10}$ Ibid., nº3866.

${ }^{11}$ Definición de altar portátil según SChulte, A.J. (1907) en The Catholic Encyclopedia, vol.I, New York. En un sentido amplio es el que puede llevarse de un lugar a otro, pero en sentido litúrgico es un ara consagrada, suficientemente grande par contener la Sagrada Hostia y la mayor parte de la base del Cáliz y se inserta sobre un altar que no sea un altar consagrado fijo. Para más información sobre altares ABAD IBÁÑEZ, J.A. y GARRIDO BONAÑO, M. (1988). Iniciación a la liturgia de la Iglesia. Madrid. pp. 111-124.

12 Otro ejemplo similar lo hallamos en Palacios Martín, B (dir.) (2000). Colección diplomática medieval de la Orden de Alcántara (1157?-1494). De los orígenes a 1454. Madrid. p.549. Tambien se tiene noticia de otro documento de la misma temática, pero todavía inédito, que ha sido transcrito por el profesor de la Universidad de León SANTIAGo Domínguez SÁnchez y trata de la concesión en 1297 de un altar portátil por parte de Bonifacio VIII a Raimundo, abad de Santa María de Ripoll. El regesto de este documento se encuentra en Digard, G., Faucon, M., Thomas, A. y Fawtier, R. (1907). Les registres de Boniface VIII, I, París. Col. 654, num. 1728. 
Diego Fernandez de León "a quien se concede este breve (-) vecino y regidor desta ciudad de Leon, thesorero y contador de los señores reyes don Henrique $3^{\circ}$ don Juan $2^{\circ} y$ don Henrique $4^{\circ}$, fue procurador de Cortes en las últimas que tuvo el dicho señor rey don Henrique $3^{\circ}$, en que pressidió el señor infante don Fernando su hermano y se offreció la differencia entre Burgos, León, Toledo y Sevilla, como lo refiere la crónica del rey don Juan el $2^{\circ}$ en el capítulo $5^{\circ}$, Año mill y quatrocientos seis." Todo ello es comprobable, ya que Diego cumple a la perfección las características del patriciado urbano anteriormente descrito, apareciendo en la documentación de la época como regidor y procurador en Cortes $^{13}$, además de Tesorero mayor de la Casa de la Moneda de Burgos ${ }^{14}$, cargo este último que le reportaría cuantiosos beneficios. Además, es el primer representante de su familia del que hay datos concretos, aunque se conoce también a un personaje de nombre Alfonso, que aparece como escribano real y procurador a finales del siglo XIV y probablemente fuera su padre.

Anteriormente se ha hablado de la vida municipal, pero también parece necesario dar una breve explicación sobre las Cortes ${ }^{15}$, ya que Diego tomó parte en varias de ellas. El sistema de elección de procurador en representación de León es entre los regidores de dicha ciudad, pero no se sabe el sistema exacto; quizás fuese por sorteo o votación, algo que se puede documentar desde finales del XV y principios del XVI, pero también parece cumplirse para todo el siglo XV, pues se repiten miembros de las mismas familias en puestos de regimiento y procurador en Cortes.

Se puede decir que la época de mayor importancia política de las Cortes es el siglo XIV, para ir en declive a lo largo del XV, ya que en los últimos años de ese siglo dejan de asistir nobleza y alto clero, pues otros órganos de la administración

13 Como regidor aparece los años 1410, 1418 y 1433 en el libro Señorío.... del profesor SANTAMARTA. Como procurador en Cortes en 1407, 1435 y 1447 lo presenta César Álvarez en su ponencia sobre linajes nobiliarios y oligarquías urbanas. Las primeras Cortes a las que asiste Diego Fernández de León fueron presididas por Fernando de Antequera, hermano del rey Enrique III y en ellas se vivió la controversia del orden en la actuación de las ciudades en Cortes. Se decidió que León era la segunda voz, tras Burgos, y antes que Toledo.

14 Álvarez C., Colección..., documento número 3527. También aparece con este cargo de Tesorero y Contador Real en: Domínguez SÁnchez, S. (2001). Colección documental de los Bachilleres de San Marcelo y de las Parroquias de Nuestra Señora del Mercado, Valencia de Don Juan y Valderas, Colección Fuentes y Estudios de historia leonesa, 92, León. En los documentos 58, 64 y 78 de la iglesia del Mercado.

15 Álvarez Álvarez, C. (coord.) (1999). Historia de León. Edad Media, León. 
permiten su participación política. El número de ciudades asistentes decrece hasta diecisiete, habiendo llegado a cien a fines del siglo XIV, pero León se mantiene ${ }^{16}$.

Continuando con las glosas del documento: "Casó el dicho contador Diego Fernández con María Fernández Cabeza de Vaca, hija y hermana de Pedro Fernández y Nuño Fernández Cabeza de Vaca, señores de Villaamete." Existen menos datos sobre la familia de María, pero parece que descendía de Tierra de Campos, probablemente de la zona de Valderas, y se ha podido localizar Villahamete en el arciprestazgo de Villalón $^{17}$, aunque actualmente sea un despoblado.

Se hace también un repaso de las posesiones del matrimonio, tanto fuera "Pobladura (..) Gordaliza de la Loma y Valdespino y parte de Morilla y Pajares.." como dentro de la ciudad de León “....sus casas principales las que hoy son iglesia y monasterio de la Concepción..”, que tenían "las armas de los Rieros, porque era este el solar y linaje del dicho Diego Fernández, y las de los Cabeza de Vaca..”, ademásde "..la casa y huerta grande que llaman del Conde, que es fuera de los muros y por la delantera sale a la calle y calzada que va de Puerta Moneda a Santa Ana y por el costado derecho y las espaldas al monasterio y campo de Sanct Francisco..". Los datos conocidos sobre estas propiedades son escasos ${ }^{18}$, pues, aunque existen documentos que atribuyen a don Diego casas cerca del corral de los Palacios del Conde don Ramiro y una gran extensión conocida como la Granja de Melgar, es difícil saber si alguna se corresponde con las enunciadas en las anotaciones marginales. Sin embargo, se puede asegurar que la propiedad situada fuera de los muros de la ciudad y junto al monasterio de San Francisco aparece en un documento referente a un hijo del matrimonio ${ }^{19}$, siendo estas notas la única noticia de que fuese una herencia. En cuanto a las posesiones fuera de la ciudad, están documentados distintos bienes y rentas en Gusendos de los Oteros, Banuncias, Cillanueva $^{20}$, en el valle de la Valdoncina, Ardón y Vega de

${ }^{16}$ Alfonso Vaca participa representando a esta ciudad en 1471 y 1473.

17 Fernández Flórez (1984). «El Becerro de Presentaciones. Códice 13 del Archivo de la Catedral de León» León y su Historia, Miscelánea histórica V, Colección Fuentes y Estudios de Historia leonesa, 32. León. pp. 263-565.

${ }^{18}$ La Orden Concepcionista. Actas del I Congreso Internacional. Vol.1, León 1990. No se ha podido encontrar ninguna información sobre la familia Vaca en lo referente al actual Convento de la Concepción, parece que siempre hubiese pertenecido a los Quiñones y no se han hallado datos sobre otro propietario anterior.

19 Álvarez C., Colección..., documento número 3893.

${ }^{20}$ Ibid., documento $\mathrm{n}^{\mathrm{0}} 3664$ (en adelante CCL). 
Infanzones $^{21}$, así como lo referente a Pobladura, pero las poblaciones enumeradas en las notas no aparecen en ninguno de los documentos consultados referentes a esta familia.

Pero el autor de estas glosas no sólo enuncia las propiedades del matrimonio Fernández de León-Vaca, sino que también informa de su devenir desde el siglo XV hasta el momento de su escritura, el siglo XVII. Así, se sabe que en las casas principales les "sucedió (..) Alonso de Vaca, señor de Pobladura, su hijo mayor (..) este vendió al duque de Valencia y de aya algunos años (...) las hubo el monasterio de la Concepción.." y que la casa y huerta del Conde, junto al monasterio de San Francisco pertenece en el siglo XVII a "Fernando Vaca, hijo de Álvaro Vaca.."

Tras la enumeración de las posesiones de la familia, se llega a la parte central de las notas, las dedicadas a la Iglesia de Nuestra Señora del Mercado, antigua del Camino $^{22}$. Aquí, se hace necesario señalar algunos datos sobre esta iglesia en la ciudad de León del siglo XV. El número de parroquias $^{23}$ no había variado en la ciudad desde el siglo XIII: San Martín, San Juan de Regla, Santa Marina, Santo Sepulcro, que en siglo XVI pasará a ser Santa Ana, San Salvador de Palaz del Rey, San Pedro de San Isidoro, San Marcelo, San Pedro de Puente Castro, San Salvador del Nido, San Pedro y San Llorente y Santa María del Camino. También está San Juan de Renueva, que existe desde siglo XII, pero pertenece a San Isidoro hasta siglo XVI. La Iglesia de Santa María del Camino o de los Francos, no es llamada del Mercado hasta principios del siglo XVII. Su origen es desconocido, se suele datar su construcción a mediados del siglo XII, aunque algunos autores la remontan al XI, siendo elevada en el emplazamiento en el que se encontraba una iglesia más antigua, probablemente del siglo X. Ha sufrido numerosas reformas que la muestran muy alterada en la actualidad, debidas seguramente en su mayor parte a reconstrucciones de elementos dañados por empujes o defectos de construcción.

Diego Fernández y su esposa "reedificaron la Capilla Mayor y gran parte de la Iglesia" y "como tales fundadores y dotadores pusieron sus armas". Se conocen

${ }^{21}$ DomínguEZ, Colección..., documento de la parroquia del Mercado n ${ }^{\circ} 66$.

${ }^{22}$ La información referente a esta iglesia se ha obtenido principalmente de ÁlvAREZ, A. (1968). La Virgen del Camino en León, Madrid 1968. y también del artículo del mismo autor (1978). "Origen y vicisitudes del templo leonés del Mercado" Tierras de León T.XVIII, n³2-33. pp. 33-48 En cuanto a la parte arquitectónica se ha recurrido a VV.AA. (1993) Arquitectura monumental en la provincia de León. León.

${ }^{23}$ SANTAMARTA. Señorío..., p.27. 
datos de reformas por un legajo de cuentas que abarca desde 1360 hasta $1440^{24}$, pero no se habla de esta reconstrucción, sino de una aportación anterior del propio Diego en 1410 que puso rejas doradas delante del altar mayor.

Pero lo más importante de esta parte central de las anotaciones marginales es el hecho de que en ella se hace referencia al motivo principal por el que se escribieron. Hubo dos pleitos entre la familia Vaca y la iglesia de Nuestra Señora del Mercado, siendo el último de ellos, donde "se prueba cómo secreta y maliciosamente borraron las armas de Rieros y Vacas", la causa de las notas que nos ocupan, dándose además en este punto de las notas datos concretos sobre dicho pleito, presentado “ante Luis Alonso, notario de la Iglesia, sentenciose en favor del canónigo Álvaro de Reinoso Cabeza de Vaca y demás descendientes de Alonso Vaca, señor de Pobladura. Año 1614”.

Una vez mencionado el asunto del pleito, las notas vuelven a la historia familiar en el punto en el que la habían dejado, es decir, en el matrimonio formado por Diego y María. Se llega ya al final de la vida de Diego "año de 1456 fallesció (..) fueron sepultados él y la dicha María Vaca su mujer en la dicha Capilla Mayor". La fecha de la muerte concuerda con un documento real ${ }^{25}$ dirigido a su hijo, Alonso Vaca, donde se le reconoce como legítimo heredero de Diego Fernández. La fecha de la muerte de María se desconoce, pues no aparece en las notas ni se ha podido documentar por otros cauces.

Así pues, la pareja fundadora de esta familia dejó "por su hijo mayor a Alonso Vaca, señor de Pobladura, que en algunas escrituras y firmas suyas se nombra Alfonso Cabeza de Vaca, fue también vezino y regidor de León, alcaide de las Torres desta cibdad, corregidor de Salamanca y murió alcalde del Adelantamiento deste reino de León ${ }^{, 26}$. Este personaje pasará a ser la figura más importante de esta familia $^{27}$ y aparece en los constantes conflictos entre el concejo y el cabildo en el

${ }^{24}$ El artículo antes citado de Arturo Álvarez da fechas concretas de los arreglos y donaciones que tuvo la iglesia del Mercado entre esos años.

25 DomínguEZ, Colección.., parroquia del Mercado, documento n ${ }^{\circ} 68$.

${ }^{26}$ SAnTAmarta, Señorío... lo sitúa como regidor en 1459, pero en el documento CCL 3664 ya ostenta ese cargo en el año 1453.Es nombrado Alcalde Mayor del Adelantamiento de León en 1469. Pero con anterioridad a todo ello es nombrado Alcaide de las Torres en 1447.

27 SANTAMARTA menciona la existencia de dos Alfonso Vaca, uno de ellos sería vecino de Valencia de Don Juan, pero en publicaciones posteriores no se hallan más referencias a este asunto, apareciendo sólo Alfonso Vaca como hijo de Diego Fernández de León (Álvarez, C.). Hay que mencionar que aparecen también otros personajes importantes con este apellido (miembros del 
siglo XV, alineándose con sus compañeros del regimiento y sobre todo con Diego Fernández de Quiñones ${ }^{28}$.

Alonso Vaca "casó la primera vez con Violante de Prado (..) y dejó por sus hijos deste primer matrimonio a Bernal, hijo mayor que murió sin hijos, y a Sebastián Vaca (..) a Diego Vaca, señor de Valdespino, (..) quedaron también del primer matrimonio otros hijos e hijas. Casó la segunda vez (..) con Violante Garavito, hija de Sancho Garavito, regidor desta cibdad, señor de Villaverde de Arcayos y de la casa fuerte de Vegacervera". La primera mujer de Alonso, Violante de Prado, aparece en algunos documentos conservados en la parroquia de Nuestra Señora del Mercado ${ }^{29}$. En cuanto a su segunda esposa, no se han encontrado datos sobre ella, pero su padre, Sancho Garavito, aparece en la documentación como regidor y procurador en Cortes, así como militante en el bando de los Quiñones del que también forma parte su yerno, Alonso Vaca.

Como descendencia "..deste segundo matrimonio tuvo a Sancho Vaca (..) a Catalina (..) a Magdalena, que fue monja de Carriço y a Inés Vaca, mujer de Hernando de Reinoso Garavito, cuios hijo, nieto y bisnieto fueron y es Álvaro y Hernando Garavito de Reinoso y Álvaro Garavito de Reinoso Cabeza de Vaca, canónigo desta Iglesia de León que defendió la dicha Capilla Mayor". A medida que se va acercando el final del texto las anotaciones se hacen de una manera más general, los personajes sólo son nombrados o definidos de una manera muy breve y parece que lo único importante es llegar al descendiente que las escribe y protagoniza el pleito con la Iglesia de Nuestra Señora del Mercado, Álvaro Garavito de Reinoso ${ }^{30}$.

Para finalizar estas anotaciones tan completas y curiosas a lo largo de dos siglos de la vida de una importante familia de la oligarquía leonesa, el autor, Álvaro Garavito, enlaza de nuevo con Alonso Vaca y su relación con la Iglesia del Mercado, verdadero motivo de estas notas: "Alonso Vaca, señor de Pobladura,

Cabildo Catedral), pero no se sabe la relación exacta con la rama de la familia de la que se está hablando.

${ }^{28}$ Conde Luna entre 1455 y 1491.

${ }^{29}$ Domínguez, Colección... Documentos de la parroquia del Mercado 67 y 78.

${ }^{30}$ Ibid., Documentos de la parroquia del Mercado 110 y 213. En ellos aparece este personaje, aunque no se hace referencia al pleito. Al aparecer en las glosas como canónigo de la iglesia de León, es de suponer que se trate de un miembro de la Catedral de León, pero no se ha podido localizar. Aun así, para una información completa del Cabildo Catedral de León es imprescindible ViLLACORTA Rodríguez, T. (1974). El Cabildo Catedral de León. Colección fuentes y estudios de Historia leonesa, 12. León. 
acrecentó la dotación antigua de la dicha Capilla Mayor de Nuestra Señora del Camino" 31 . Y es que las escrituras y "todo lo arriba referido (fueron) presentadas en el pleito de la Capilla este año de 1614 ante Luis Alonso en que tuvimos sentencia favorable. Sea Dios loado por todo. Amén”.

Estas notas suponen una importantísima fuente de información para el conocimiento de una de las familias que componía el patriciado urbano de León desde el siglo XV. Se conocían ya numerosos datos sobre ella, gracias a los profesores César Álvarez y Jose María Santamarta, a quienes se cita en numerosas ocasiones a lo largo de este trabajo, pero no se tenía una historia vertebrada con tanta claridad como la ofrecida por el propio Álvaro Garavito de Reinoso, miembro de la familia y defensor de sus derechos sobre la Capilla Mayor de la Iglesia de Nuestra Señora del Mercado, en sus notas. Gracias al pleito con esta iglesia y al intento de Álvaro Garavito de demostrar la relación de su familia con ella, se conserva hoy esta valiosa información histórica.

Pero, aunque las notas marginales se hayan constituido en la parte central y más novedosa a nivel histórico de este trabajo, también resulta interesante el estudio diplomático del documento papal alrededor del cual están escritas, ya que la documentación pontificia suele aparecer descrita de un modo bastante genérico ${ }^{32}$, utilizando el término bulla para cualquier documento papal, sin intentar una clasificación más concreta. Sin embargo, dentro del grupo de documentos intitulados por el Papa, validados con sello de plomo, escritos en latín y con el pergamino como materia escriptoria, hay distintas subdivisiones o tipos documentales $^{33}$, según cuál sea el motivo o las circunstancias de expedición del documento.

Así, el documento objeto de estudio se encuentra dentro de las litterae gratiosae, es decir, cartas de merced en las que se conceden gracias sencillas, como indulgencias, confirmación de privilegios o un altar portátil, siendo este último el caso del documento que Eugenio IV envía a Diego Fernández de León y a su mujer.

31 Álvarez, A. La capilla mayor se restaura en 1484 y los arcos de las naves se reconstruyen a lo largo del siglo XV, pero no hay referencias a Alonso o Alfonso Vaca.

32 En las colecciones diplomáticas en las que se recogen todo tipo de documentos, es frecuente hacer referencia a los documentos pontificios de un modo general, sin distinguir tipos documentales.

${ }^{33}$ Para el estudio diplomático se ha seguido a RABIKAUSKAS, S.J. (1994) Diplomatica Pontificia, Roma. También a Frenz, T. (1989) I documenti pontifici nel medioevo e nell' età moderna, Ciudad del Vaticano. 
Suelen tener los márgenes bastante adornados, al igual que el nombre del Pontífice. Las iniciales de las palabras de la primera línea también suelen adornarse, aunque esto varía según la importancia del destinatario y el grado de solemnidad que se quiera dar al documento, por ello, el que se transcribe en este artículo, destinado a un miembro de una oligarquía local, es bastante sencillo, sin ornamentos especiales. A pesar de la sencillez que le caracteriza, se aprecia la existencia de nexos especiales entre las letras "ct" y "st", sólo utilizado en las litterae solemnes y gratiosae.

Las litterae son documentos con una formulística muy rígida, lo que facilita su clasificación. La intitulación es común a todas ellas "Eugenius episcopus, seruus seruorum Dei" y tras ésta se sitúa la directio, que se inicia con las palabras "dilecto filio" ${ }^{34}$.

Tras esto se encuentra la salutatio típica también de todas las litterae, menos de las llamadas solemnes, "salutem et apostolicam benedictionem".

El cuerpo documental se suele iniciar con un preámbulo, donde se señala la devoción del destinatario, que primeramente ha tenido que solicitar la gracia luego concedida por este documento. Esto se debe a que este tipo de documentos se realizan a partir de una súplica, es decir, de una solicitud previa del destinatario del documento al Papa.

Tras la dispositio, que suele ser bastante escueta, como se comprueba en este documento, se sitúa la sanctio, que en las litterae gratiosae se compone de dos cláusulas fijas "Nulli ergo omnino hominum liceat hanc paginam nostre concessionis infringere uel ei ausu temerario contraire. Si quis autem hoc attemptare presumpserit indignationem omnipotentis Dei et Beatorum Petri et Pauli, Apostolorum eius, se nouerit incursurum."

Por último, hay que hablar de la validación con el sello de plomo que, en este tipo documental, debería estar pendiente de hilos de seda rojos y amarillos, pero que no se conserva. En la actualidad sólo se conoce su existencia por los dos orificios en el pergamino, por donde debieron pasar en su momento esos hilos de seda.

En conclusión, se puede decir que este pergamino, en su conjunción de un documento pontificio y anotaciones marginales, supone un gran avance para el

${ }^{34}$ En este caso, pues cuando el documento se dirige al rey, la fórmula es "Carissimo in Christo filio" y cuando va dirigida a un obispo es "venerabili fratri". 
seguimiento de esta familia del patriciado leonés a lo largo de dos siglos, ya que, hasta este momento, toda la información existente sobre ella se basaba en documentos sueltos e invertebrados, dando lugar fácilmente a confusiones, mientras que ahora, con estos nuevos datos, se tiene una historia bastante coherente de la familia Fernández de León-Vaca.

\section{APÉNDICE DOCUMENTAL}

1435, octubre, 18. Florencia.

Litterae gratiosae de Eugenio IV a Diego Fernández de León concediéndole la posesión de un altar portatil, para poder oficiarmisa en cualquier sitio.

A. ASIL, 56. Perg. orig. de 352 x $504 \mathrm{~mm}$. Letra gótica cancilleresca. Buen estado de conservación. Márgenes izquierdo e inferior llenos de notas sobre la familia del destinatario del documento.

Reg.: PÉRez LlamaZARes, J. (1923). Catálogo de los códices y documentos de la Real Colegiata de San Isidoro de León. León, p. 100.

EUGENIUS episcopus, seruus seruorum Dei. Dilecto filio Didaco $P$ Fernandi de Leon, domino loci de Pobladura, legionensis diocesis, et dilecte in Christo filie .. eius impresentiarum vxori, salutem et apostolicam $\beta$ benedictionem.

Sincere deuotionis affectus, quem ad nos et Romanam geritis ecclesiam, non indigne meretur ut petitionibus uestris illis presertim $A_{\text {A }}$ quas ex deuotion[i]s feruore prodire conspicimus, quantum cum Deo possumus, fauorabiliter annuamus. Hinc est quod nos, uestris deuotis $\bar{\rho}$ supplicationibus inclinati ut liceat uobis et cuilibet uestrum habere altare portatile, cum debita reuerentia et honore, super quo, in locis ad hoc $p$ congruentibus et honestis possitis, per proprium uel alium sacerdotem ydoneum missam et alia diuina officia, sine iuris alieni preiudi $P$ cio, in uestra ac familiarium uestrorum domesticorum presentia facere celebrari, deuotioni uestre, tenore presentium, indulgemus. Nulli ergo $\&$ omnino hominum liceat hanc paginam nostre concessionis infringere uel ei ausu temerario contraire. Si quis autem hoc attemptare $P$ presumpserit, indignationem omnipotentis Dei et Beatorum Petri et Pauli, Apostolorum eius, se nouerit incursurum.

Datum Florentie, ${ }^{10}$ anno Incarnationis Dominice millesimo quadringentesimo tricesimo quinto, quintodecimo kalendas nouembris, pontificatus nostri anno quinto. 


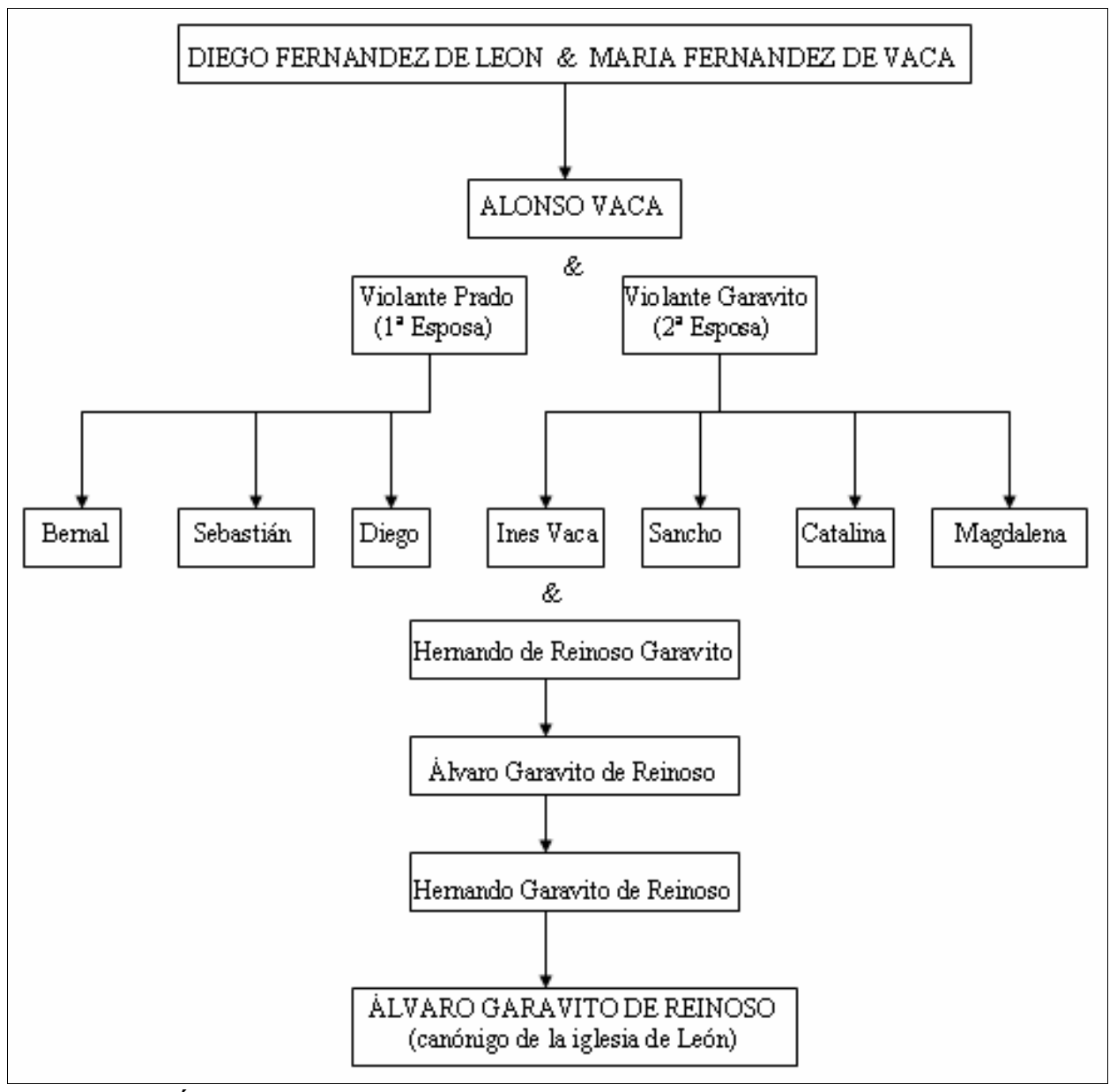

Árbol genealógico de la familia Fernández de León-Vaca 
